\title{
1.
}

\section{Un gráfico del Templete de San Pietro in Montorio}

\author{
Joan Bassegoda i Nonell
}

Existen antiguas y modernas representaciones gráficas del templete que Donato Bramante edificó, en 1502, por impulso de los Reyes Católicos en la colina romana del Gianicolo.

Un dibujo conservado en el Museo de los Ufizzi de Florencia (A 135) se ha tenido por el diseño original de Bramante pero en opinión de Peter Murray sería más lógico fecharlo en la segunda mitad del siglo XVI y por el hecho de aparecer en el fondo de una pintura de Federico Fiori, il Barocci (1535-1612) podría pensarse que fuere éste el autor del dibujo.

Pero existen diversas representaciones posteriores a 1502, fecha que ha quedado demostrada como la de erección del monumento, ya que al dorso de la lápida empotrada en el frontal del altar de la cripta, tal como explicó José Sancho Roda $^{2}$ desmontando las hipótesis de A. Prandi en la voz "Bramante" de la Enciclopedia cattolica, de Angelis d'Ossat y R. Bonelli en Da Bramante a Michelangelo, Venecia, 1960 reproducidas por Paolo Portoghesi en la Enciclopedia di architeturra e urbanística, Vol. I, Istituto Editoriale Romano, $1968^{3}$. El argumento de estos críticos se basaba en la inexistencia del tempietto en la Guía de Roma de E. Albertini Opusculum de mirabilius novae et veteris urbis Romae de 1510, en la que figuran algunas obras de Bramante pero no el tempietto que, por tanto, sería posterior a tal fecha. La lápida en el frontal del altar de la cripta estuvo inicialmente en los cimientos del templete y, en 1638, fue hallada al practicar un nuevo acceso a la cripta momento en que se colocó en el frontal del altar hasta la restauración de 1998 en qué se desmontó y se pudo leer en el reverso la inscripción SECELLUM APOSTOLOR PRINCI MARTIRIO SACRUM. FERDINAND HISPAN REX ET HELISABE REGINA CATHOLICI POST ERECTAM AB EIS AEDEM POSSI. AN SALXPIANE MDII.

Las representaciones gráficas más antiguas posteriores a esta fecha corresponden al grabado, supuestamente de 1503, localizado en la Biblioteca Nacional de Madrid durante las investigaciones previas a la restauración, a una ilustración del Codex Correr del Soane Museum de Londres y a las xilografías de los tratados de Serlio y Palladio.

BASSEGODA i NONELL, Joan: "Un gráfico del Templete de San Pietro in Montorio", en Boletín de Arte, n” 23, Universidad de Málaga, 2002, págs. 603-608. 
Sebastiano Serlio lo incluyó con texto y dibujos en su Tercer Libro de Arquitectưa de $15600^{5}$. Por su parte, Andrea Palladio en su Libro Cuarto ${ }^{6}$ presenta una planta y alzado distintos de los de Serlio y también de la realidad de la obra ejecutada. Estos dibujos de Palladio están incluidos en la parte dedicada a las antigüedades romanas, diciendo que Bramante fue el primero en volver a la luz la bella y buena arquitectura de los antiguos que había quedado escondida por lo que había decidido darle lugar entre los antiguos ${ }^{7}$.

También Giorgio Vasari menciona el templete en su Le vite de'più celebre architetti... y pintores y grabadores más tardíos reproducen el edificio bajo diversas interpretaciones como es el caso de Rafael Sanzio en los Desposorios de la Virgen, Romolo Cincinato (1610) en la cúpula de El Escorial, Agostino Carracci (1557-1602) en un grabado ilustración de la Eneida de la Real Academia de Bellas Artes de San Fernando, Giovanni Battista Piranesi (1720-1778) y Giovanni B. Falda (1640-1700c.)

\section{LAS GUIAS DE ROMA}

El colegio Oficial de Arquitectos de Aragón editó en 1990 un facsímil del libro Cosas maravillosas de la santa ciudad de Roma impreso originalmente en aquella ciudad en $1729^{8}$. Viene precedido de un estudio de Ramón Betrán Abadía sobre los Mirabilia Urbis Romae en la que se expone y comenta la historia de las diversas guías de Roma que arranca del siglo XII con manuscritos destinados a los romeros y peregrinos a Roma para ver las maravillas de la ciudad y ganar indulgencias. Mediado el siglo XII se dio a conocer el Mirabilia Urbis Romae de Benedetto Canonico que fue muchas veces copiado incluyendo las extrañas fantasías acerca de la ciudad y sus monumentos.

"MURRAY, R: Voz: "Bramante" Macmillan Encyclopedia of Architects, vol. I The Free Press New York, 1.982, págs. 276-277.

2 SANCHO RODA, J.: "El templete de Bramante, restaurado" Restauración \& Rehabilitación, $\mathrm{n}^{\text {o }}$ 30, Madrid, julio de 1999, págs. 26-35.

${ }^{3}$ ALBERTINI, E.: Opusculum de mirabilis novae et veteris Roma, Rona, 1510, citado por BRUSCHI, A., Dizionario Enciclopedico dell' Architettura e I'Urbanística, Vol, I, Roma Istituto Editoriale Romano, 1968, pág. 410.

${ }^{4}$ SANCHO RODA, J., "Proyecto de restauración del templete de Bramante" Restauración \& Rehabilitación, $n^{\circ}$ 18, Madrid, julio de 1998, págs. 28-37.

${ }^{5}$ SERLIO, S.: Il terzo libro de Architettura nel quale si figurano e describono le antichitè di Roma e le altre que sono in Italia e fuor d'Ytalia G. B. e Marchio Sena, fratelli, Venecia, 1560, págs. 38-41.

${ }^{6}$ PAILADIO, A.: I quattro libri di Architettura, Libro IV, Cap. XVII, Donino de'Franceschi, Venecia, 1579, págs. 64-66.

${ }^{7}$ Ibídem

${ }^{8}$ Cosas maravillosas de la santa ciudad de Rona Arquitectura de los precursores. Sexto título, Edición facsímil de la de Zenobi de 1729, Zaragoza, Delegación en Zaragoza del Colegio de Arquitectos de Aragón, 1990. 


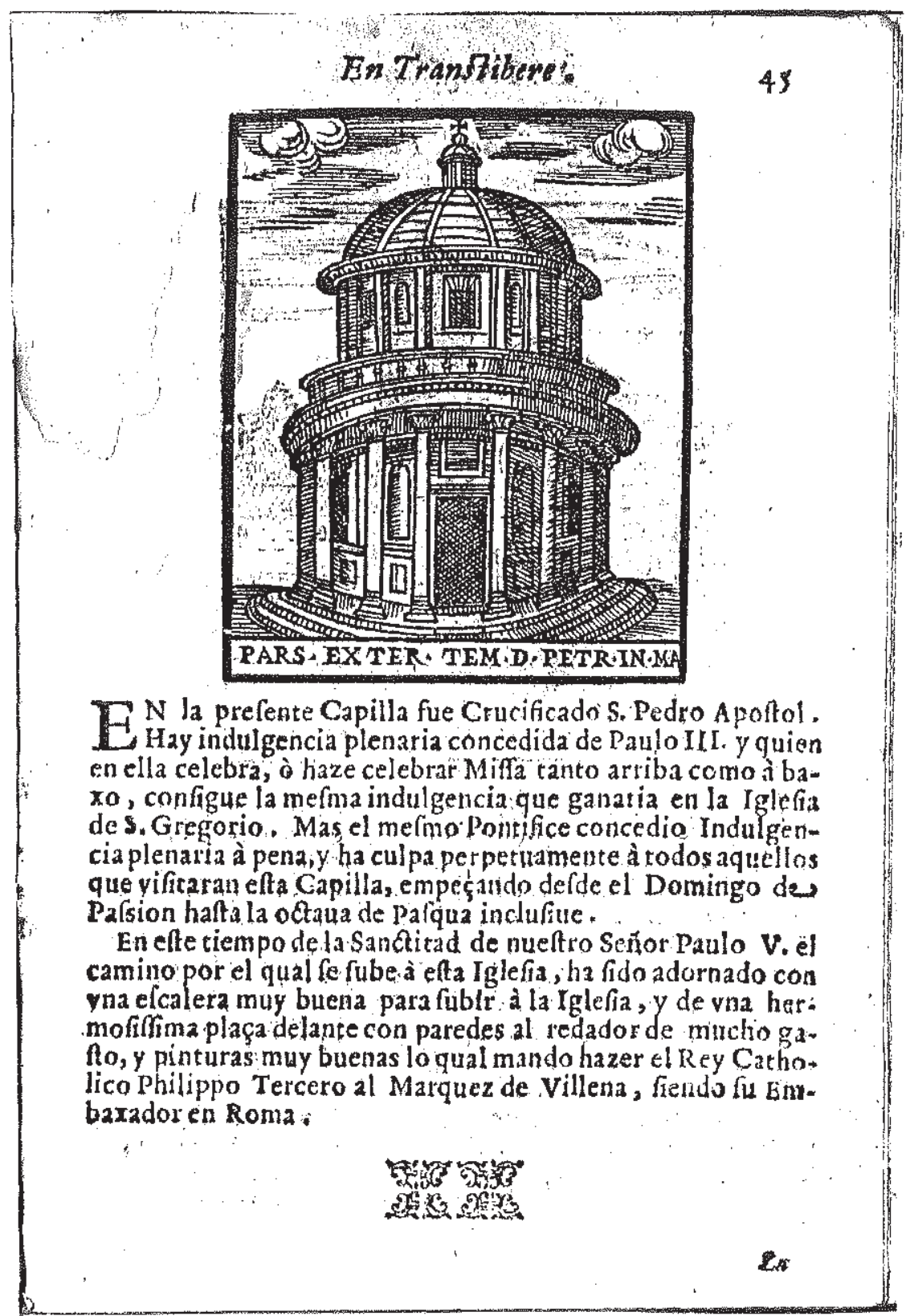

1. San Pietro in Montorio. Grabado publicado en 1610 por Io. Antón Franzini y herederos de Hieronimo Franzini en una guía sacra de Roma. Biblioteca de la Real Cátedra Gaudí 
Cuando los libros pudieron imprimirse se siguieron publicando gufas hasta la inclusión de Palladio en su $N$ Libro de Arquitectura de la descripción de las antiguallas de Roma basada en los viejos Mirabilia, influyendo notablemente en las guias posteriores.

En el siglo XVII se publicó el Viaggio per Roma per vedere le pitture que in esa si trovano de Marcini y a fines del siglo XVI e inicios del XVII las guías de Roma impresas en castellano en la Ciudad Eterna.

Girolamo Franzini dio a conocer el Libro de las maravillas de Roma dedicado al Santísimo Padre Sixto $V$, seguido del tratado de las antigüedades de Roma por Palladio y las iglesias de Roma con sus reliquias. Del modo de ganar indulgencias, significación de lo Agnusdei. La sucesión de los romanos Pontifices, emperadores y otros príncipes cristianos y guia de peregrinos en ediciones de 1589, 1600, 1610 y 1619.

Otra guía fue la de Pietro Martire Feline de Cremona Las antigüedades figuradas del alma de la ciudad de Roma y el tratado nuevo de las cosas maravillosas de la ciudad de Roma y la de Gabriel Díaz Vara Calderón en 1673 publicada en Madrid y, ya en el siglo XVIII, la de Giovanni Battista Vacondio en 1711 y 1720 y la de Pedro León en 1729.

De 1750 es la Roma ampliata e rinovata o sia vera descrizione dell'antica e moderna città di Roma de Ottavio Pulcinelli que se vendía en la librería de Gregorio Riosecco. Este volumen figura en la Biblioteca de la Real Cátedra Gaudí procedente de la colección del arquitecto José Casademunt Torrens (1804-1868) ', segundo director de la Clase de Arquitectura de la Lonja entre 1835 y 1868, al suceder a Antonio Celles Azcona (1775-1835).

El libro, encuadernado en piel de cuero badanilla, está dedicado al cardenal Giovanni Battista Spinola, del título de Santa Maria degli Angeli, abad perpetuo comanditario de la insigne abadía de Subiaco y Prefecto de la Sagrada Congregación de la Inmunidad. Este volumen estaba a la venta en la librería de Gregorio Roisecco en la plaza Navona, junto a la iglesia de Santa Agnese in Agone. Contiene en bandera un mapa de Roma en perspectiva caballera titulado Novae Urbis Delinatio. La dedicatoria es del librero autor de la reimpresión de la obra al cardenal Spinola en el año jubilar de 1750.

Se divide en nueve Jornadas o Itinerarios seguidas de una cronología de los Sumos pontífices hasta Benedicto XIV, que ocupan 194 páginas en octavo y un

\footnotetext{
${ }^{9}$ BASSEGODA i NONELL, J.: "El primer arquitecte de l'Acadèmia" Butlletí, IVVV, Reial Academia Catalana de Belles Arts de Sant Jordi, Barcelona, 1991.
} 
indice analítico. Por lo que se refiere a San Pietro in Montorio hay una descripción del convento franciscano incluida en la Jornada Segunda que describe los monumentos desde la puerta de Santo Spirito hasta el Trastevere. Da cuenta de las obras de arte existentes en el convento de Franciscanos Reformados y dedica tan sólo tres líneas al tempietto de Bramante: Nellatrio del convento, la capella rotonda eretta nel sito dove fu crocefisso S. Pietro, è architettura di Bramante, sin ilustración ni grabado alguno.

Más interesante es otro volumen de la Biblioteca de la Real Cátedra Gaudí, encuadernado en pergamino, procedente igualmente de la colección Casademunt, adquirida en 1970 a sus descendientes, las familias de los arquitectos Vilar, Casademunt y Serrallach ${ }^{10}$.

Corresponde a la edición de 1610 por lo. Antón Franzini y herederos de Hieronimo Franzini, dedicado el 20 de enero de 1610 al señor don Francisco de Castro, duque de Taurisano y conde de Castro, Embajador de Su Majestad en la Corte de Roma. Redactado en lengua castellana con inclusión del número de todas las iglesias, parroquias bautismales, parroquias simples, monasterios, colegios, hospitales, compañías y otros lugares píos de la Alma Ciudad de Roma.

En la página 44 se trata de la iglesia de San Pietro in Montorio, en el Trastevere, con un grabado al boj de su fachada y, en la página 45, otro grabado a la madera representando el templete con el título al pie de PARS.EXTER.TEM.D.PETR.IN.MA y, a seguido el texto En la presente capilla fue crucificado S. Pedro Apóstol. Hay indulgencia plenaria concedida por Paulo III y a quien en ella celebre o hagar celebrar misa, tanto arriba como abajo, consigue la misma indulgencia que ganaría en la iglesia de San Gregorio. El mismo Pontifice concedió indulgencia plenaria a pena y a culpa perpetuamente a todos aquellos que visitaran esta capilla empezando desde el domingo de Pasión hasta la octava de Pascua siguiente. En este tiempo de la Santidad de nuestro Señor Paulo V el camino por el cual se sube a la iglesia ha sido adornado con una escalera muy buena para subir a la iglesia y una hermosísima plaza delante con paredes alrededor de mucho gasto y pinturas muy buenas lo cual lo mandó hacer el rey católico Felipe III al marqués de Villena, siendo su embajador en Roma.

Con todo no hay mención de Bramante. Lo singular de esta guía es que contiene la descripción de los edificios de Roma en castellano hasta la página 208. En la siguiente aparece la Jornada Primera de la guía de Roma en Italiano, y a continuación las Jornadas segunda y tercera hasta la página 211. Viene luego el indice de Sumos Pontifices hasta Paulo V, romano. A continuación se halla

\footnotetext{
${ }^{10}$ José Vilar Roca (1799-1879); Josep Casademunt Torrens (1804-1868); Leandre Serrallach
} Mas (1837-1890). 
L'Antichità figurate dellalma città di Roma originalmente de Prospero Parisio, aumentada y nuevamente escrita por Fray Pedro Mártir Felinii de Cremona, de la Orden de los Servitas. Sigue el catálogo de reyes y emperadores romanos, de los reyes de España, Francia y los Dogos de Venecia.

Se trata de la encuadernación de dos fragmentos de fibros distintos y lenguas diferentes con la única coincidencia de la correlación de páginas numeradas, aunque no de los textos.

Las representaciones y levantamientos de planos del tempietto realizadas posteriormente son innúmeras, especialmente en tratados de Historia de la Arquitectura de época reciente. Baste mencionar los cuidadosos grabados al acero del libro de Paul Lateroully, Edifices de Rome Moderne, L. Tiranti, Londres, s.a., el Wasmuths Lexikon der Baukunst, Berlin, 1929, el Fletcher-Calzada Historia de la arquitectura por el método comparado, Canosa, Barcelona, 1931 o el Corrado Ricci Baukunst un Dekorative Plastik der Hoch-und Spät-Renaissance in Italien, Julius Hoffmann, Stuttgart, 1923 y, naturalmente, los completísimos planos realizados en ocasión de la restauración de 1998. 